\title{
A IDENTIDADE DO PROFESSOR DE EDUCAÇÃO FÍSICA: UM PROCESSO SIMULTANEAMENTE BIOGRÁFICO E RELACIONAL
}

\author{
PHYSICAL EDUCATION TEACHERS' IDENTITY: A PROCESS AT ONCE \\ BIOGRAPHICAL AND RELATIONAL
}

\section{LA IDENTIDAD DEL PROFESOR DE EDUCACIÓN FÍSICA: UN PROCESO SIMULTÁNEAMENTE BIOGRÁFICO Y RELACIONAL}

\author{
Inês Cardoso*, Paula Batista*, Amândio Graça*
}

\begin{abstract}
Palavras-chave
Docentes.

Escolha da

profissão.

Acontecimentos

que mudam a vida.

Resumo: A construção da identidade docente é um processo biográfico e relacional de reapropriação crítica das experiências vividas ao longo da vida (DUBAR, 1997). Este estudo, de natureza qualitativa, analisa as reflexões acerca das práticas de seis estagiários de Educação Física para compreender a influência das suas experiências prévias na opção pela profissão, a interpretação das imagens que identificaram como mais representativas do significado de "ser professor" e as transformações sentidas ao longo do processo formativo. Os estagiários valorizaram a diversidade de experiências, a capacidade de envolverem os alunos nas suas aprendizagens e os momentos de partilha com os outros professores.
\end{abstract}

Keywords

Faculty.

Career choice.

Life-changingevents.

Palabras clave

Docentes.

Elección de

profesión.

Acontecimientos que

cambian la vida.

Abstract: Building teachers' identity is a biographical and relational process of critically re-appropriating lifelong experiences (DUBAR, 1997). This qualitative study examines reflections about six student teachers' practices in order to understand the influence of their previous experiences on their career choice, the interpretation of the images they saw as most representative of what "being a teacher" means, and the changes they underwent throughout their education. Student teachers valued diversity of experiences, ability to involve students in their learning processes, and moments of sharing with other teachers.

Resumen: La construcción de la identidad docente es un proceso biográfico y relacional de reapropiación crítica de las experiencias vividas a lo largo de la vida (DUBAR, 1997). Este estudio, de naturaleza cualitativa, analiza las reflexiones sobre las prácticas de seis estudiantes de Educación Física en práctica para comprender la influencia de sus experiencias previas en la opción por la profesión, la interpretación de las imágenes que han identificado como más representativas del significado de "ser profesor" y las transformaciones que han sentido a lo largo del proceso formativo. Los estudiantes en práctica han valorizado la diversidad de las experiencias, la capacidad de comprometer a los alumnos en sus aprendizajes y los momentos compartidos con los demás profesores.
* Universidade do Porto. Porto, Portugal. E-mail: inestcardoso@gmail.com.

Recebido em: 11-03-2015 Aprovado em: 22-01-2016 (c) (1) (8) Licence 


\section{INTRODUÇÃO'}

Tornar-se professor é um processo longo e complexo, de natureza multidimensional, idiossincrásica e contextual (DINKELMAN; MARGOLIS; SIKKENGA, 2006, FLORES; DAY, 2006, AKKERMAN; MEIJER, 2011). Pode-se dizer que a identificação com a profissão tem início na infância e se prolonga por mais de doze anos passados em espaços escolares, numa vivência rodeada de imagens de professores, fonte de crenças pessoais acerca do que significa ser professor (ZEICHNER, 1992, COLLAY, 2006, MARCON; GRAÇA; NASCIMENTO, 2010).

As experiências prévias (ENTWISTLE, 1995), vividas em contextos socioculturais específicos, inscrevem-se na biografia e influenciam as escolhas dos candidatos à formação de professores. As identidades sociais herdadas (PADILHA; NELSON, 2011) e as expectativas acerca da docência, oriundas de processos de socialização antecipatória (DUBAR, 1997), filtram as experiências da formação e as possibilidades de aprendizagem. Cada professor constrói a sua identidade profissional (IP) de um modo próprio e singular. Dubar (1997) sublinha que qualquer IP resulta de um processo simultaneamente biográfico e relacional, ligado à história de vida do indivíduo, às vivências familiares, escolares e profissionais, à identificação e diferenciação construídas na relação social e na experiência da ação. Flores e Day (2006) reconhecem a influência de três fatores contextuais no processo de (re)construção da identidade profissional do professor: as experiências prévias, a formação inicial e o impacto do contexto de trabalho (cultura escolar).

Os valores, imagens e crenças sedimentados por socialização antecipatória podem ser problematizados, desconstruídos e reconstruídos durante a formação profissional através das interações estabelecidas e da interiorização de novos significados (BERGER; LUCKMANN, 2004, BARBOSA-RINALDI, 2008), permitindo que os formandos se constituam como sujeitos de sua própria formação (SANTOS; BRACHT; ALMEIDA, 2009). Neste contexto, os processos de reapropriação crítica das experiências vividas (SFARD; PRUSAK, 2005, MARCELO, 2009a) articulam-se com a própria trajetória biográfica (BOLÍVAR, 2007), carecendo, todavia, de ferramentas auxiliares para confrontar o núcleo duro das crenças e representações prévias com conceções alternativas de ser professor, não confináveis a mera atividade académica desprovida de consequências para a construção da IP. Sem atender às autobiografias dos estudantes, sem tomar em consideração nem desafiar as crenças que eles trazem para a formação, sem ter em conta a realidade dos contextos em que a socialização profissional acontece, ficarão fortemente limitadas as possibilidades de influenciar positivamente ao nível da preparação para o ensino (TOMLINSON, 1999) e da (re)construção da IP (DOWLING, 2011). A qualidade da formação depende das oportunidades proporcionadas aos estagiários, quer nas instituições de ensino superior, quer nas escolas, que, em muitos casos, são marcadas por descontinuidades e fragmentação, em vez de integração e continuidade, evidenciando falta de articulação entre teoria e prática (FLORES, 2010, CALDERHEAD; SHORROCK, 1997, SILVA; ANDRADE; ZANELLI, 2010).

O objetivo deste estudo é examinar o contributo das experiências prévias de estagiários de EF na identificação com a profissão, e de que modo as suas crenças e representações sobre ser professor, em geral, e professor de EF, em particular, se transformam com as experiências vividas em contexto de trabalho e como contribuem para a (re)construção da sua IP.

1 Artigo elaborado no âmbito do projeto de investigação "O papel do estágio profissional na (re)construção da Identidade Profissional no contexto da Educação Física", financiado pela Fundação para a Ciência e Tecnologia (PTDC/DES/115922/2009). 


\title{
2 RECONSTRUÇÃO DAS CRENÇAS E REPRESENTAÇÕES DA IDENTIDADE PROFISSIONAL
}

Tornar-se professor é uma viagem pessoal profunda, na qual o estagiário considera as suas crenças e tenta reconciliá-las com as expectativas da universidade, da comunidade educativa, dos alunos e seus familiares e, em última análise, consigo próprio. Por se tratar de um processo de interiorização da noção de "pertença" à profissão (BATISTA; QUEIRÓS, 2013), emergir como um profissional reflexivo envolve a vontade de ser um participante ativo num processo de crescimento, negociado, vivido e praticado (LARRIVEE, 2008, SACHS, 2001, NEIRA, 2012), no qual se pode revelar a capacidade de agenciamento do estagiário na reprodução criativa da estrutura social (GIDDENS, 1997, MACPHAIL; TANNEHILL, 2012) e o tipo de pessoa e de professor reconhecido pelos outros. Acomodar-se, contestar, negociar o tipo de identidade imputada ou reconhecida através de sistemas interpretativos histórica e culturalmente construídos com base nas características naturais, institucionais, discursivas, ou afiliativas da pessoa (GEE, 2001) sublinha a dimensão relacional da construção da identidade, que tem na linguagem o seu instrumento mais importante (BERGER; LUCKMANN, 2004, SAVATER, 2013). Tal como referem Berger e Luckmann (2004, p. 49), é a partir da linguagem utilizada que se torna possível reconhecer como é que os sujeitos se posicionam perante as diversas situações ou acontecimentos:

\begin{abstract}
Falo como penso e o mesmo faz o meu interlocutor. Ambos ouvimos o que cada um diz no mesmo instante, o que torna possível um contínuo, sincronizado e recíproco acesso às nossas duas subjetividades, uma proximidade intersubjetiva na situação frente a frente, que nenhum outro sistema de sinais consegue duplicar. Mais ainda, ouço-me enquanto falo. Os meus próprios significados subjetivos tornam-se atingíveis por mim, de maneira objetiva e contínua e, ipso facto, passam a ser 'mais reais' para mim.
\end{abstract}

A linguagem utilizada por cada interlocutor para revelar o seu posicionamento (ao outro ou a ele próprio) está imbuída de uma forte componente emocional, que poderá ser acedida através da clareza do discurso/narrativa ou do autodiálogo (SFARD; PRUSAK, 2005, ENYEDY; GOLDBERG; WELSH, 2006), num apelo à reflexão que, por força das emoções, permite ao estagiário intervir no contexto de forma intencional, tornando-se um agente ativo e resiliente (WAUGH; THOMPSON; GOTLIB, 2011), num processo dinâmico e evolutivo de reconfiguração, renovação e reconstrução da IP (ZEMBYLAS, 2003, DAY et al., 2006, FLORES; DAY, 2006). A linguagem utilizada pelos estagiários pode ser captada com recurso a diferentes ferramentas promotoras de reflexão. A captação de imagens acompanhadas de narrativas poderá ser uma delas.

\section{IMAGENS COMO INSTRUMENTO DE CRÍTICA REFLEXIVA}

Assim como as narrativas, também as imagens e as metáforas constituem recursos para os estagiários reconfigurarem as suas IP e as explicitarem para si próprios e para os outros (GÓMEZ, 1992, ALSUP, 2003). O uso de imagens ou metáforas pode ajudar os estagiários a comunicarem ideias profundamente arraigadas sobre as suas perceções e expectativas relativas ao ensino (GREENE; MAGLIARO, 2005), a revelarem aquilo que é mais profundo e de cariz mais emocional e, por essa via, permitir explorar a dimensão tácita e emocional do conhecimento pessoal da prática. Berger e Luckmann (2004, p. 139) acrescentam que “...há 
boas razões para se acreditar que sem esta ligação emocional com os outros significados, 0 processo de aprendizagem seria difícil, senão impossível".

A (re)construção do conhecimento prático pelos estagiários nos diferentes contextos da formação opera mais favoravelmente num processo dinâmico e colaborativo, no qual todos os intervenientes interiorizam a sua experiência de participação (MARCELO, 1992, KELLY, 2006). Neste processo, as imagens tornam-se uma ferramenta produtiva de reflexão, não apenas para os estagiários, mas também para os investigadores que pretendam uma melhor compreensão da complexidade de se tornar professor (GREENE; MAGLIARO, 2005). As imagens representativas das crenças pessoais podem ser elicitadas e partilhadas através de meios verbais ou audiovisuais, incluindo a captação de fotos ou vídeos de situações vividas ou recortadas dos media e apropriadas ou modificadas para atribuição de um significado pessoal. Esta ligação entre as imagens pessoais e as imagens escolhidas ajuda o estagiário a concetualizar e a fazer emergir as suas ideologias educacionais pelo facto de o levar a pensar em metáforas baseadas na sua história de vida e no seu conhecimento prático (ALSUP, 2003, SANCHO; HERNÁNDEZ, 2004).

Em suma, a par de instrumentos mais usuais como as entrevistas e as reflexões escritas, a elicitação de imagens poderá contribuir para o aprofundamento da crítica reflexiva, em prol da melhoria das práticas e da (re)construção das IP.

\section{METODOLOGIA}

\subsection{Contexto do estudo}

Este estudo insere-se num projeto de investigação centrado no estágio profissional para professores de EF. Tem como cenário duas escolas da rede pública ( $7^{\circ}$ ao $12^{\circ}$ anos de escolaridade), inseridas em duas zonas urbanas do litoral norte de Portugal. Cada uma dessas escolas acolhe um núcleo de estágio constituído por três estagiários, assistidos por um professor da escola cooperante ${ }^{2}$ e por um orientador da faculdade que tutela a formação inicial. O modelo de prática supervisionada adotado privilegia uma experiência em contexto real, em que cada estagiário assume a responsabilidade da docência de uma das turmas do professor cooperante $(\mathrm{PC})^{3}$, durante todo 0 ano letivo. $\mathrm{O}$ âmbito de ação dos estagiários não se circunscreve à componente letiva ${ }^{4}$, inclui também 0 envolvimento nas atividades do departamento ${ }^{5}$, grupo disciplinar ${ }^{6}$ e direção de turma ${ }^{7}$; nos projetos de extensão à comunidade (desporto escolar ${ }^{8} \mathrm{e}$ visitas de estudo).

2 Estabelecimento de ensino básico e/ou secundário onde funcionam os Núcleos de Estágio e que assegura o desenvolvimento de atividades de iniciação à prática profissional docente, incluindo a prática de ensino supervisionada. Os ensinos básico e secundário correspondem, respetivamente, ao ensino fundamental e ao ensino médio, no sistema educativo brasileiro.

3 Professor a exercer funções na escola de acolhimento do estagiário, que acompanha o futuro professor, orientando-o no exercício da prática profissional.

4 Em Portugal, o horário de trabalho do pessoal docente em exercício de funções integra uma "componente letiva" e uma "componente não letiva". A "componente letiva" corresponde ao número de horas lecionadas e abrange todo o trabalho desenvolvido com as turmas ou grupos de alunos. 5 Os departamentos curriculares são constituídos pelos docentes de grupos de recrutamento afins. Entre outras competências, cabe aos departamentos: a planificação dos planos de estudo e a adoção de metodologias específicas destinadas ao seu desenvolvimento; a análise e a adoção de estratégias diversificadas e de formas de atuação, orientadas para a melhoria das aprendizagens dos jovens; a reflexão e análise sobre as práticas educativas e respetivo contexto.

6 É uma estrutura de apoio ao departamento curricular, constituído pelo conjunto de docentes do mesmo grupo de recrutamento (ex. Educação Física). 7 Função desenvolvida pelo Diretor de Turma, a quem cabe assegurar a articulação entre os professores da turma, promover estratégias conducentes à resolução de problemas dos alunos e fomentar a participação dos encarregados de educação na vida escolar dos seus educandos. Corresponde em alguns países à figura do Class Head-Teacher, Le Professeur Principal ou ainda El Tutor de Clase. 


\subsection{Participantes}

Participaram voluntariamente neste estudo os seis estagiários dos núcleos de estágio das duas escolas públicas selecionadas no ano letivo 2011/12. Cada núcleo era constituído por dois elementos do género feminino e um do género masculino, cujas idades variavam entre 22 e 25 anos. Três estagiários tinham frequentado o curso tecnológico de desporto no ensino secundário e mostravam-se mais extrovertidos e mais confiantes perante os alunos. Um dos estagiários distinguia-se pela sua persistência, capacidade de comunicação e expressividade. A relação entre os estagiários era pautada por um espírito de união e de respeito mútuo de companheirismo e amizade.

Foi solicitada, a cada estagiário, a declaração de consentimento livre e informado, apensa a um formulário contendo a devida informação relativa aos objetivos do estudo e às características da participação. A confidencialidade e anonimato foram garantidos através da supressão dos elementos identificadores dos participantes.

\subsection{Instrumentos e procedimentos de recolha}

Foram realizadas três sessões de grupo focal (outubro, novembro e janeiro), duas entrevistas individuais (novembro e julho) e duas oficinas (fevereiro e maio). Cada participante elaborou um diário de campo, de reflexão pessoal acerca das emoções e das transformações percebidas ao longo de todo o processo de estágio. A primeira sessão do grupo focal incidiu sobre as motivações e influências para escolher a profissão e as expectativas relativas à formação. As sessões seguintes incidiram sobre os sentimentos vividos na realidade escolar $\mathrm{e}$ partilha de reflexões anotadas nos diários de campo.

O guião da primeira entrevista individual integrou questões acerca das expectativas, do impacto do contexto escolar e do que significa ser professor, em geral, e ser professor de $\mathrm{EF}$, em particular. $\mathrm{O}$ guião da entrevista final integrou questões acerca do balanço retrospetivo relativo às expectativas, às experiências mais marcantes e aos resultados alcançados em termos pessoais e profissionais.

Para a primeira oficina os estagiários trouxeram imagens captadas durante uma semana de trabalho na escola, para ilustrar as suas práticas (duas fotos por cada área de desempenho: organização e gestão do ensino e da aprendizagem; participação na escola; relação com a comunidade; e desenvolvimento profissional). Para a segunda oficina selecionaram imagens (fotos e vídeos) para representar denotativa ou metaforicamente o significado de ser professor de EF. Em ambas as oficinas os participantes expunham as imagens, os motivos da escolha e o significado que lhes atribuíram.

\subsection{Procedimentos de análise}

As falas dos participantes nas sessões de recolha de dados foram gravadas em áudio ou vídeo, transcritas integralmente e enviadas aos respetivos intervenientes para confirmação e eventuais esclarecimentos ou comentários adicionais. 0 material das transcrições e dos diários de campo foi introduzido no programa de análise qualitativa NVivo 9, que facilitou a aplicação de procedimentos de análise de conteúdo (BARDIN, 2004) e de comparação constante (MERRIAN, 2009). 
O material incluído nas três categorias definidas a priori deduzidas de Dubar (1997): i) componente biográfica; ii) componente relacional; iii) relação entre a componente biográfica e a componente relacional; foi categorizado a posteriori, a partir da análise das unidades de significado, através do método de comparação constante, usado para fazer emergir padrões e temas nas representações dos estagiários (GLASER; STRAUSS, 1999, MERRIAN, 2009). Este procedimento aplicado a todas as fontes de dados e categorias deu lugar a uma leitura mais seletiva, para retenção dos temas mais salientes dentro das categorias a priori, e interpretação dos seus significados e interações. A triangulação da evidência encontrada nos temas e padrões pelas diferentes fontes de dados e a busca ativa de evidência negativa permitiram dar consistência à extração de conclusões sobre o modo como os estagiários se perceberam a si próprios e, consequentemente, inferir acerca do modo como (re)construíram a sua IP.

\section{RESULTADOS E DISCUSSÃO}

\subsection{Componente biográfica}

Os dados põem em evidência a importância das experiências prévias na determinação da escolha da profissão, assim como na reconfiguração do significado de ser professor de EF. As experiências desportivas desde tenra idade (em alguns casos, desde os três anos); o gosto pela prática desportiva; e a influência de professores e/ou treinadores destacam-se nas razões da escolha da profissão, mantidas mesmo se desaconselhados por familiares, ou incentivados para opções social e economicamente mais favoráveis.

Eu senti a pressão da família... Quando disse que queria ser professora de EF, os meus pais começaram a dizer: 'Professora? Mas não vais ter emprego fixo, vais andar aqui, vais andar ali, vai ser complicado. Tens a certeza?' Ao início foi um choque. É lógico que os pais querem sempre o melhor para nós, e se pudesse ter um emprego certo, perto de casa, era fantástico (M/GF1).

As imagens construídas ao longo do tempo fortaleceram a identificação com a área profissional e a vontade de se tornarem professores capazes de fazer a diferença. As perceções e as expectativas profissionais que os estagiários desenvolvem durante as experiências prévias influenciam a identificação com a profissão, o modo como encaram o ensino e o investimento que fazem no seu desenvolvimento profissional (COLLAY, 2006, REID et al., 2008, CHONG; LOW, 2009). Segundo Meijer, Graaf e Meirink (2011), o desenvolvimento da IP envolve a (re) construção de significados ao longo do tempo.

As experiências marcantes, quer positivas, quer negativas, que os estagiários vivenciaram enquanto alunos e enquanto atletas são evocadas para melhor atuarem enquanto professores,

A maneira como ele (professor de Biologia) convivia connosco, o clima positivo de aprendizagem que ele nos facultava (sempre com respeito e mantendo bem a hierarquia), a motivação que ele suscitava em nós, tudo isso para mim tem transferência para a EF... Sem dúvida que para mim foi a grande referência. Eu costumava dizer que queria ser como ele, porque ele é fabuloso, mesmo. E ele nem era de EF, mas acho que tanto os bons professores como os maus, para mim têm muita, muita influência (M/GF1).

A maior parte das experiências é relembrada e contada com emoção. Enquanto as experiências positivas lhes serviram de referência e de inspiração, as experiências negativas motivaram-nos a quererem ser melhores profissionais e a proporcionarem melhores experiências 
aos seus alunos, como, por exemplo: "A maior parte dos professores [de EF] foram um mau exemplo: perguntavam 'o que é que vocês querem? Peguem lá uma bola'. Isso fez-me pensar: se eu fosse professor fazia-o de outra maneira...". (R/GF1)

De acordo com Choi (2007), as identidades são pontos instáveis de identificação, representadas e negociadas através de discursos, num contexto histórico-cultural. Não se trata de uma essência, mas de um posicionamento. No exemplo apresentado, o participante revela a sua tomada de posição perante a experiência que lhe estava a ser imposta, e que, simultaneamente, o motivou a querer vir a ser um professor capaz de marcar a vida dos seus alunos.

\subsection{Componente relacional}

Das múltiplas tarefas que os professores desempenham na escola, os estagiários referem-se à prática letiva, à participação nos conselhos de turma ${ }^{9}$, à participação nas reuniões de departamento e de grupo disciplinar, ao acompanhamento do diretor de turma e à participação no clube de desporto escolar. Um dos participantes refere ainda a vigilância de exames e a participação na atualização de documentos estruturantes da escola. Todas estas formas de envolvimento na escola, todas as vivências do dia a dia de um professor são encaradas por todos como extremamente significativas para a construção da sua IP.

As palavras dos estagiários carregam uma certa carga emocional e afetiva, sobretudo quando se referem ao relacionamento com os alunos, à capacidade de os envolver e alcançar os objetivos de aprendizagem:

Por muito que queira chegar ao final desta jornada, ver o quanto cresci e quanto cresceram os meus alunos, ver naquilo que eles se transformaram, tudo quanto mudou. Cada dia que dou uma nova aula é mais um dia perto do final de tudo isto, de tudo o que agora me define, e eu gosto de estar assim, gosto tanto! Não queria que acabasse (M/DB/ p. 55).

Os estagiários entendem que o professor deve ser o responsável por conseguir envolver os alunos na aprendizagem. Como narra um dos participantes: "...a experiência com esta turma deixou-me uma mensagem fundamental: não é possivel ensinar quem não quer aprender, mas é responsabilidade do professor estimular os alunos para a aprendizagem" (T/ $\mathrm{DB} /$ p. 39). O relacionamento com os alunos e a prática desportiva prazerosa são as referências cruciais. Um participante diz, ao apresentar uma foto dos seus alunos em atitude de festejo: "O aluno deve praticar desporto com prazer. Se o aluno tiver prazer, vai consolidar melhor as aprendizagens" (V/W2). A comunicação da afetividade por palavras e gestos aparece como chave do sucesso pedagógico:

O facto de serem dois alunos mais introvertidos fez com que a minha abordagem fosse diferente, procurando salientar mais os aspetos positivos e respondendo sempre com um gesto que Ihes permitisse percecionar que estavam a evoluir, tal como 'um piscar de olho'... Penso que esta forma de procurar que o aluno se sinta confiante para tentar ultrapassar a dificuldade é essencial para o sucesso [...] (R/ $\mathrm{DB} / \mathrm{p} .22)$

O poder de chegar aos alunos é uma marca distintiva da EF. Um participante fala da sua experiência: "[...] os alunos sentem mais afinidade connosco. Nós chegamos mais rapidamente

90 conselho de turma é uma estrutura educativa responsável pela organização, acompanhamento e avaliação das diferentes atividades a desenvolver pela turma. É constituído pelos professores da turma, pelo aluno delegado de turma (representante dos colegas) e por dois representantes dos pais e encarregados de educação da turma. 
a eles e percebemos melhor as suas angústias" (C/W2). Outro participante relata a história surpreendente contada pelo diretor da sua turma, professor de outra disciplina: "[...] na escola de [...], onde fui professor durante muitos anos, cheguei a fazer aulas de EF. E porquê? Porque queria conhecer os meus alunos, queria saber como eles realmente eram. Queria aproximarme deles e a sala de aula não me dava essa oportunidade" (T/DB/p.15).

A autonomia dos alunos e os modelos de ensino que a promovem merecem destaque especial no quadro de preocupações pedagógicas dos estagiários: "[...] na organização das tarefas é preciso dar tempo aos alunos. Os alunos têm que perceber o que é para fazer e têm que saber organizar-se" (V/W2). O Modelo de Educação Desportiva (MED) encaixa bem nestas preocupações, e os desafios e benefícios da aplicação do MED são resumidos assim:

Encaro a minha atuação em contexto MED como um desafio, uma vez que o domínio do conteúdo é ainda mais premente do que nas abordagens mais tradicionais à Educação Física. É um Modelo que se baseia no questionamento como forma de aprendizagem concreta, na constante colocação de desafios. $\mathrm{E}$ face a um problema ou desajuste eu não posso simplesmente responder pelos alunos, tenho que os orientar no sentido da descoberta por si e para si (M/DB/p. 22).

A aplicação do Projeto Individual de Progresso nas modalidades de ginástica acrobática e de futebol constitui um outro exemplo de fomento de autonomia e de responsabilidade:

Eram eles que vinham ter comigo e diziam: 'Professora, hoje tem que me avaliar nisto ou naquilo'. Eu avaliava-os, também na parte da responsabilidade. Se eles conseguissem cumprir o objetivo, passavam hierarquicamente para o objetivo seguinte. Se não, continuávamos a trabalhar naquele. E deu bastantes frutos [... ] saber o que fazer para ultrapassar as dificuldades (M/EF).

Para os estagiários, atividades extracurriculares foram interpretadas como um excelente veículo de motivação para os alunos, como uma forma privilegiada de envolver os encarregados de educação na vida escolar dos seus educandos e como um incentivo à prática regular do exercício físico, extensivo a familiares e amigos:

O melhor foi termos crescido! De uma corrida para a outra, éramos mais e melhor, vieram amigos e até alguns pais. Fazíamos a ligação entre a escola, as aulas, os alunos e os pais. Como eu queria isto! Partilhar vivências, mostrar o trabalho que os seus filhos realizam, envolvê-los na nossa esfera, conversar com eles, responder a questões, ver os olhos brilhantes de novidade e de interesse [...]. E eu estava feliz (M/DB/pp.39-40).

Três dos participantes destacaram o seu contributo e os benefícios da intervenção junto dum centro social que acolhe crianças e jovens desfavorecidos e duma instituição de pessoas portadoras de deficiência:

Ser professor está associado à responsabilidade social de contribuir para a formação de outrem. Sentir que se fez parte desta contribuição social é a maior gratificação que se pode ter como pessoa, pois a recompensa do trabalho exercido surge em cada sorriso e em cada rosto feliz das crianças (T/DB/p.31).

Em suma, na componente relacional, a dimensão pessoal (emocional, afetiva) não pode ser dissociada da dimensão profissional. Ser professor "vai para além das aulas e mesmo para além da escola" (T/W1). É "marcar os alunos e fazer a diferença" (V/W1), é "ensinar a cooperar, a partilhar, a viver com os outros e para os outros" (T/W2), é "ter paixão pelo que se faz" (VN2) e "ser entusiasta" (J/W1). E é exatamente essa paixão pelo que se faz que promove a ação, a 
resiliência e o agenciamento (GIDDENS, 1997, SACHS, 2001, MACPHAIL; TANNEHILL, 2012). É também essa paixão pelo que se faz que promove a vontade de se ser um professor transformador (SACHS, 2003, MOCKLER, 2005), empenhado em transformar a sociedade através da formação de seres humanos que pensem criticamente e que alterem hábitos, crenças e ideias preconcebidas, colocando em evidência a perspetiva humanista, também defendida por Molina Neto (2003).

Ao fim e ao cabo isto é até um bocado utopia, e até cliché, mas ser professor é também ajudar a transformar o mundo, não é? É ajudar a transformar alguma coisa. E se não for o mundo inteiro, é o mundo de cada um de nós (M/EF).

Esta vontade de intervir no mundo leva a que, através da linguagem, explícita ou tácita, se projete a alteração da estrutura social (BERGER; LUCKMANN, 2004) e se veja a escola e 0 professor como oficina e artífice do humano.

Ser professor é um estado de alma: és professor ou não és professor'. O professor deve ser, sem dúvida, um veículo de formação dos alunos. Na EF eu trabalho aspetos psicossociais (a proximidade, o trabalho de grupo, a competição, etc.), trabalho aspetos motores e estou também a trabalhar aspetos cognitivos. Portanto, é uma formação muito, muito completa (M/EI).

\subsection{Relação entre a componente biográfica e a componente relacional}

As crenças e expectativas que os estagiários trazem consigo, formadas através de uma aprendizagem por observação (LORTIE, 1975) e reativadas durante a formação inicial, entrecruzam-se com as experiências de estágio (SCHERER; MOLINA NETO, 2000), saindo reforçadas, postas entre parêntesis, ou então desafiadas, neste caso, quando as novas experiências contradizem claramente as expectativas. Foi o caso dos participantes das duas escolas estudadas, que, contrariamente às suas expectativas, reconheceram a existência de um trabalho colaborativo entre os professores dos diversos grupos disciplinares. Notaram um clima de empenho, cooperação e respeito no seio do grupo de EF. Alguns ficaram surpreendidos com a cultura profissional e a dedicação demonstrada pelos professores:

[...] a minha ideia era encontrar professores que não [...] se preocupassem muito com a prática, que já estivessem há não sei quantos anos no ensino, e a verdade é que não. São professores preocupados com a prática, com uma entreajuda, uma relação e uma comunicação fantásticas. Aliás o grupo de EF é reconhecido na escola pelo seu envolvimento, [...] é aquele que mais habilitações académicas tem $[\ldots .$.$] e é reconhecido na escola como um grupo [...] competente e trabalhador, que$ promove atividades [...] e acho que isso é bem visível nos outros professores (J/El).

O trabalho colaborativo que se assiste nas comunidades de prática explicadas por Wenger (1998) potencia as aprendizagens e promove o desenvolvimento do conhecimento prático (KELLY, 2006, MARCELO, 2009b). Todos aprendem com todos através de um espírito de abertura e de processos de reconhecimento das posições assumidas (GEE, 2001, COHEN, 2010). Os estagiários aprendem com os membros do núcleo de estágio, com os professores de EF e com os professores de outros grupos disciplinares. Por seu turno, os outros professores também aprendem com eles, com o que trazem de novo para a escola, sem preconceitos nem medo de serem mal interpretados:

Eu pensei 'como é que vai ser e como é que não vai ser? Será que sim?' Mas aquilo é espetacular. Muita abertura. O que nós sabíamos [...], por exemplo, em relação ao $\mathrm{MED}^{10}$, que era uma novidade, nenhum dos professores que estavam na escola

10 Modelo de Educação Desportiva. 
teve formação ao nível do MED [...]. Por exemplo, há aqueles professores que dizem: 'Ah não, não! Os estagiários? Por amor de Deus! Não vou aprender nada com eles.' E eles não! 'O MED? Mas como é que é isso? Explica-me lá que eu até acho interessante (M/EF).

Esta aprendizagem recíproca entre os estagiários e os professores (incluindo o PC), defendida por Bopsin, Silva e Molina Neto (2010), potencia a reflexão e o questionamento através da partilha de experiências e ideias (LOUGHRAN, 2009; BARBOSA-RINALDI, 2008). Ao PC é atribuída uma importância acrescida, na medida em que se encontra numa posição privilegiada para promover a reflexão, ao criar situações propositadas que apelam à ligação entre a componente biográfica e a componente relacional, que integre os aspetos profissionais e pessoais (KORTHAGEN, 2009; SANTOS; BRACHT; ALMEIDA, 2009).

Relativamente à aula observada (ao PC) foram cometidos pelo professor erros propositados com o objetivo de nós os identificarmos, sem conhecimento prévio e para nos alertar do que não pode fazer um professor (V/DB/p.10).

O sentimento de pertença à escola e à profissão não se restringe a espaços de partilha do saber ou do saber fazer. Ele somatiza-se no reconhecimento do modo como somos olhados, como somos aceites, e no conforto que isso nos proporciona:

Desde as 8 h que estávamos na escola com o objetivo de ajudar na organização do corta-mato... à medida que o tempo passava, sentia que estava a ser tratado como um qualquer professor de EF. Senti-me a entrar verdadeiramente na organização escolar, fora da sala de aula. Se até agora 'parecia' que estava só a assistir, a partir deste dia, senti-me melhor entre os professores. Parece que começamos a entrar no mundo deles e a fazer parte do grupo de $E F$ (R/DB/p.10).

Em alguns casos, os estagiários conseguem colocar em prática as suas ideias, outras vezes não (WILSON; FLODEN; FERRINI-MUNDY, 2002). Quando os futuros professores são percebidos como uma ameaça, encontram resistência por parte dos professores, tornando a experiência formativa desencorajadora (STROOT; KO, 2006).

Ser olhado e respeitado como professor é o Rubicão que qualquer estagiário quer ver definitivamente atravessado. Pô-lo em causa, sobretudo perante os alunos, por melhor que seja a intenção, jamais será bem aceite. Os estagiários dos dois núcleos tiveram neste aspeto experiências distintas, evidenciadas nos seguintes excertos:

[...] o nosso PC nunca se metia nas nossas aulas, jamais a não ser que fosse alguma coisa de vida ou de morte a acontecer, mas isso nunca aconteceu (M/EF).

[...] A PC decidiu intervir e 'tomar as rédeas da aula'. Mas pior do que isso, ... a professora enganou-se na coreografia. Ela estava a fazer uma coisa e eu outra (tendo eu a certeza de que estava certo). Naturalmente que os alunos se confundiram, e claro, a ideia que ficou no ar foi a de que a professora mais experiente tinha razão, quando de facto não foi isso que aconteceu... Conclusão, em dez minutos poderia 'destruir' a confiança que os alunos têm no professor (R/DB/p. 31).

A participação plena num grupo de pertença requer uma atitude ativa (SACHS, 2001, ADAMS, 2011), de agenciamento (GIDDENS, 1997, MACPHAIL; TANNEHILL, 2012), exige aprofundamento da reflexão crítica, o abandono da zona de conforto (DAY, 1998) e a passagem da fronteira do que começa por se apresentar como exigência externa e se vem a interiorizar como pessoalmente gratificante: 
estágio e, portanto, era importante realizá-las. Agora, continuam a ser uma das incumbências do estágio, mas agora, e passo a expressão, eu faço-as porque me apetece. Sinto-me verdadeiramente motivada para as fazer. E comparar aquilo que escrevia há 42 aulas com aquilo que hoje escrevo: é abismal (M/ $\mathrm{DB} / \mathrm{p} .41)$

A reflexão é entendida por muitos autores (e.g. ZEMBYLAS, 2003, KORTHAGEN; VASALOS, 2005, KELLY, 2006) como um indicador do nível de desenvolvimento profissional. $\mathrm{E}$, nesse desenvolvimento, as crenças e representações do significado de ser professor vão-se alterando, num jogo de reconstrução das imagens que acompanham o indivíduo desde tenra idade, que se constitui como um processo dinâmico, evolutivo, relacional e necessariamente contextualizado. Um dos participantes mostra, de forma sui generis, o seu sentimento acerca da evolução do seu nível de reflexão: "... .sinto-me o upgrade dos meus conhecimentos [...]" (M/ EF), e acrescenta como evidência prática: "...não digo sempre, mas na maior parte das aulas os miúdos saíam com algo de melhor e eu também” (M/EF). Esse processo vai de encontro ao defendido por Dubar (1997) e por Flores e Day (2006), ao considerarem os fatores biográfico e relacional, ambos contextualizados histórica e socialmente. A tomada de consciência deste processo está patente na seguinte expressão:

Hoje dei por mim a pensar que daqui a três aulas já não volto a dar ginástica. Faznos pensar e relembrar como o tempo é fugaz, e em tudo aquilo que já construímos juntos: as dificuldades que ultrapassamos, aquilo que aprendemos, as crenças que permaneceram e aquelas que se desvaneceram (M/DB/p.20).

Segundo Korthagen e Vasalos (2005), a reflexão é importante para os professores tomarem consciência das suas qualidades, de modo a poderem utilizá-las de forma mais intencional e sistemática. Larrivee (2008) defende que emergir como prático reflexivo envolve a vontade de ser um participante ativo, acreditar na possibilidade de transformação e enfrentar abertamente os erros, as dificuldades e incompreensões que sempre surgem. Porém, como referem Flores e Day (2006, p. 230), "[...] despite the strong connections between personal biography and stable sense of identity, it is clear that in most if not all cases, history was mediated by context". Neste estudo, a história de cada estagiário cruza-se com as relações que se estabelecem no contexto específico da sua prática, pelo que as vivências formativas revelam estreita colaboração entre a universidade e a escola e articulação entre teoria e prática, situação defendida por alguns autores (BOPSIN; SILVA; MOLINA NETO, 2010, IZA; NETO, 2015).

\footnotetext{
E tenho a certeza que, no meio disto tudo, eventualmente irão aparecer outras modalidades para as quais não estarei tão preparada, não terei tantos conhecimentos, mas sei que através da partilha, através do processo de formação contínua vou conseguir chegar lá. Porque a minha formação teórica e a minha experiência académica, de alguma forma, deu-me valências para eu conseguir de facto procurar toda essa informação que me ajudará a ser melhor professora ( $\mathrm{T} /$ $\mathrm{EF})$.
}

\section{CONCLUSÕES}

Esta pesquisa detalha a interação que se estabelece entre a biografia pessoal, a componente relacional e as influências contextuais de estagiários de EF. As experiências vividas, bem como os sentimentos que emergiram das relações que se foram estabelecendo, 
constituíram a base da (re)construção da IP, nos planos individual e coletivo. Os resultados colocaram em evidência que a transformação das crenças e autorrepresentações como professores de $E F$, nomeadamente no que se refereà responsabilidade do professor na formação integral dos alunos, ao espírito de partilha entre os professores e à vontade em investir no desenvolvimento profissional numa lógica de aprendizagem ao longo da vida, é influenciada pela perceção do contexto e das relações que aí se estabelecem. Ambientes pautados pelo trabalho colaborativo, em que se cultiva a partilha e se apoia a iniciativa, favorecem um envolvimento profícuo, estimulador da vontade de (se) transformar. A formação inicial, e mais concretamente a experiência de estágio, desempenha um papel fulcral no processo de socialização profissional dos professores de EF. Deve dar resposta à necessidade de preparar os futuros professores para o desenvolvimento de práticas reflexivas e investigativas, acompanhando as mudanças que operam na escola nos tempos atuais (SANCHO; HERNÁNDEZ, 2004) e as necessidades de uma sociedade em permanente mudança (WILSON; FLODEN; FERRINI-MUNDY, 2002).

Os instrumentos de recolha de dados complementaram-se entre si. Uns sem os outros não ofereceriam um quadro tão completo e multifacetado acerca dos pensamentos e das experiências de aprendizagem dos participantes. As entrevistas em profundidade e os diários de bordo deram acesso à perspetiva mais pessoal de cada participante. As sessões de grupo focal e as oficinas promoveram a partilha e o cotejo de ideias entre todos os participantes. A captação de fotos/vídeos do dia a dia da sua prática e a seleção de imagens criativas e metafóricas constituíram uma experiência genuinamente enriquecedora, ajudaram os participantes a organizar o pensamento e a exprimir ideias e representações da realidade que de outra forma lhes passariam despercebidas.

Deixar de se sentir estudante para passar a sentir-se professor é vivido como uma espécie de metamorfose. Todos os participantes referiram, sobretudo, sentimentos positivos nessa passagem, valorizando a diversidade das experiências proporcionadas pelo contexto de estágio profissional, a capacidade de envolverem os alunos nas suas aprendizagens e os momentos (formais e informais) de reflexão partilhada com os outros professores. Referiramse ainda à importância atribuída à interação que conseguiram estabelecer com os seus alunos fora da sala de aula, à participação na escola e na comunidade, à responsabilidade em criar oportunidades de prática desportiva para todos os jovens da comunidade educativa e ao trabalho colaborativo desenvolvido entre os membros do núcleo de estágio para a construção de um conhecimento prático.

A cultura e organização das escolas onde decorreu o estágio, a atitude profissional e acolhedora dos professores e 0 ambiente de trabalho e sentimento de pertença cultivados no núcleo de estágio, em estreita colaboração com a universidade, proporcionaram condições contextuais favoráveis para uma identificação positiva com a profissão, baseada no autodesenvolvimento reflexivo, na vontade de valorizarem a EF e fazerem a diferença para os seus alunos, de serem inovadores e de cuidarem do seu desenvolvimento pessoal e profissional. A criação e manutenção de parcerias eficazes entre escolas e universidades, no sentido de constituírem comunidades de prática, é crucial para a formação de professores de EF, porquanto proporciona uma relação de reciprocidade, reconhecendo as potencialidades de cada instituição na (re)construção da IP (FLORES, 2010, IZA; NETO, 2015).

No futuro, será interessante aprofundar como é que o conhecimento prático vai sendo construído no interior das comunidades de prática - núcleos de estágio e escolas -, quais as 
experiências formativas que facilitam ou dificultam a integração e a agência dos estagiários e qual a sua repercussão na (re)construção da IP do professor de EF.

\section{REFERÊNCIAS}

ADAMS, Ruth. Exploring dual professional identities, the role of the nurse tutor in higher education in the UK: role complexity and tensions. Journal of Advanced Nursing, Barking, Essex, v. 67, n. 4, p. 884-892, 2011.

AKKERMAN, Sanne; MEIJER, Paulien. A dialogical approach to conceptualizing teacher identity. Teaching and Teacher Education, Philadelphia, v. 27, n. 2, p. 308-319, Aug. 2011.

ALSUP, Janet. English education students and professional identity development: using narrative and metaphor to challenge preexisting ideologies. Pedagogy: Critical Approaches to Teaching Literature, Language, Composition, and Culture, Durham, v. 3, n. 2, p. 277-280, Spring 2003.

BARBOSA-RINALDI, leda. Formação inicial em Educação Física: uma nova epistemologia da prática docente. Movimento, Porto Alegre, v. 14, n. 3, p. 185-207, set./dez. 2008.

BARDIN, Laurence. Análise de conteúdo. 3. ed. Lisboa: Edições 70, 2004.

BATISTA, Paula; QUEIRÓS, Paula. O estágio profissional enquanto espaço de formação profissional. In: BATISTA, Paula; QUEIRÓS, Paula et al. Olhares sobre o Estágio Profissional em Educação Física. Porto: FADEUP, 2013. p. 33-52.

BERGER, Peter; LUCKMANN, Thomas. A construção social da realidade: um livro sobre a sociologia do conhecimento. 2. ed. Lisboa: Dinalivro, 2004.

BOLÍVAR, Antonio. The initial training of secondary school teachers and their professional identity.

Ese-Estudios Sobre Educacion, Navarra, n. 12, p. 13-30, 2007.

BOPSIN, Andressa; SILVA, Lisandra; MOLINA NETO, Vicente. Contribuições do grupo de pesquisa F3P-EFICE para a formação de professores e Prática Pedagógica na ESEF/UFRGS e na Rede Municipal de Ensino de Porto Alegre. Movimento, Porto Alegre, v. 16, p. 189-216, 2010. n. esp.

CALDERHEAD, James; SHORROCK, Susan. Understanding teacher education: case studies in the professional development of beginning teachers. London: Falmer, 1997.

$\mathrm{CHOI}$, Soo Joung. The experiences of non-native English speaking teachers and their professional identity constructions in an ESL context. 2007. Dissertação (Doctor of Philosophy in Secundary and Continuing Education) - Graduate College of University of Illinois at Urbana, Champaign, 2007.

CHONG, Sylvia; LOW, Ee-Ling. Why I want to teach and how I feel about teaching-formation of teacher identity from pre-service to the beginning teacher phase. Educational Research for Policy and Practice, Singapore, n. 8, p. 59-72, 2009.

COHEN, Jennifer. Getting recognised: Teachers negotiating professional identities as learners through talk. Teaching and Teacher Education, Philadelphia, v. 26, n. 3, p. 473-481, 2010.

COLLAY, Michelle. Discerning professional identity and becoming bold, socially responsible teacherleaders. Educational Leadership and Administration: Teaching and Program Development, Washington, DC, v. 18, p. 131-146, 2006.

DAY, Christopher. Working with the different selves of teachers: beyond comfortable collaboration.

Educational Action Research, London, v. 6, n. 2, p. 255-275, Dec. 1998.

DAY, Christopher et al. The personal and professional selves of teachers: stable and unstable identities. British Educational Research Journal, London, v. 32, n. 4, p. 601-616, Agos., 2006. 
DINKELMAN, Todd; MARGOLIS, Jason; SIKKENGA, Karl. From teacher to teacher educator: experiences, expectations, and expatriation. Studying Teacher Education, Philadelphia, v. 2, n. 1, p. 5-23, May 2006.

DOWLING, Fiona. 'Are PE teacher identities fit for postmodern schools or are they clinging to modernist notions of professionalism?' A case study of Norwegian PE teacher students' emerging professional identities. Sport, Education and Society, London, v. 16, n. 2, p. 201-222, Mar. 2011.

DUBAR, Claude. A socialização: construção das identidades sociais e profissionais. Porto: Porto, 1997.

ENTWISTLE, Noel. The use of research on student learning in quality assessment. In: GIBBS, Graham. Improving student learning through assessment and evaluation. Oxford: Oxford Brookes University, 1995. p. 24-43.

ENYEDY, Noel; GOLDBERG, Jennifer; WELSH, Kate. Complex dilemmas of identity and practice. Science Education, Malden, v. 90, n. 1, p. 68-93, Nov. 2006.

FLORES, Maria. Algumas reflexões em torno da formação inicial de professores. Educação, Porto Alegre, v. 33, n. 3, p. 182-188, set./dez. 2010.

FLORES, Maria; DAY, Christopher. Contexts which shape and reshape new teachers' identities: a multiperspective study. Teaching and Teacher Education, Philadelphia, v. 22, p. 219-232, Nov. 2006.

GEE, James. Identity as an Analytic Lens for Research in Education. Review of Research in Education, Washington, DC, v. 25, p. 99-125, 2001.

GIDDENS, Anthony. Modernidade e identidade pessoal. 2. ed. Oeiras: Celta, 1997.

GLASER, Barney; STRAUSS, Anselm. The discovery of grounded theory: strategies for qualitative research. New York: Aldine de Gruyter, 1999.

GÓMEZ, Angel. O pensamento prático do professor: a formação do professor como profissional reflexivo. In: NÓVOA, António. Os professores e a sua formação. Lisboa: Dom Quixote, 1992. p. 93-114.

GREENE, Carol; MAGLIARO, Susan. Pre-Service Teachers' Images of Teaching. Advances in Research on Teaching, Bingley, v. 11, p. 207-234, 2005.

IZA, Dijnane; NETO, Samuel. Os desafios do estágio curricular supervisionado em Educação Física na parceria entre universidade e escola. Movimento, Porto Alegre, v. 21, n. 1, p. 111-124, jan./mar. 2015.

KELLY, Peter. What is teacher learning? A socio-cultural perspective. Oxford Review of Education, Oxford, v. 32, n. 4, p. 505-519, Sept. 2006.

KORTHAGEN, Fred. A prática, a teoria e a pessoa na aprendizagem profissional ao longo da vida. In: FLORES, Maria; VEIGA SIMÃO, Ana. Aprendizagem e desenvolvimento profissional de professores: contextos e perspectivas. Mangualde: Edições Pedago, 2009. p. 30-60.

KORTHAGEN, Fred; VASALOS, Angelo. Levels in reflection: core reflection as a means to enhance professional growth. Teachers and Teaching, London, v. 11, n. 1, p. 47-71, Aug. 2005.

LARRIVEE, Barbara. Meeting the Challenge of Preparing Reflective Practitioners. New Educator, New York, v. 4, n. 2, p. 87-106, 2008.

LORTIE, Dan. School-teacher: a sociological study. Chicago: University of Chicago Press, 1975.

LOUGHRAN, John. A construção do conhecimento e o aprender a ensinar sobre o ensino. In: FLORES, Maria; VEIGA SIMÃO, Ana. Aprendizagem e desenvolvimento profissional de professores: contextos e perspectivas. Mangualde: Pedago, 2009. p. 17-37.

MACPHAIL, Ann; TANNEHILL, Deborah Helping Pre-Service and Beginning Teachers Examine and Reframe Assumptions About Themselves as Teachers and Change Agents: "Who is Going to Listen to You Anyway?". Quest, London, v. 64, n. 4, p. 299-312, Oct., 2012. 
MARCELO, Carlos. A formação de professores: novas perspetivas baseadas na investigação sobre o pensamento do professor. In: NÓVOA, António. Os professores e a sua formação. Lisboa: Dom Quixote, 1992. p. 51-76.

MARCELO, Carlos. Desenvolvimento Profissional Docente: passado e futuro. Sísifo. Revista de Ciências da Educação, Sevilha, n. 8, p. 7-22, jan./abr. 2009a.

MARCELO, Carlos. Formality and informality in the learning-to-teach process. Revista de Educación, Madrid, n. 350, p. 31-55, 2009b.

MARCON, Daniel; GRAÇA, Amândio; NASCIMENTO, Juarez. Estruturantes da base de conhecimentos para o ensino de estudantes-professores de Educação Física. Motriz, Rio Claro, v. 16, n. 3, p. 776-787, jul./set. 2010.

MEIJER, Paulien; GRAAF, Gitta; MEIRINK, Jacobiene. Key experiences in student teachers' development. Teachers and Teaching, London, v. 17, n. 1, p. 115-129, Feb. 2011.

MERRIAN, Sharan. Qualitative research and case study applications in education. San Francisco: Jossey-Bass, 2009.

MOCKLER, Nicole. Trans/forming Teachers: New Professional Learning and Transformative Teacher Professionalism. Journal of In-service Education, London, v. 31, n. 4, p. 733-746, 2005.

MOLINA NETO, Vicente. Crenças do professorado de Educação Física das escolas públicas de Porto Alegre - RS/Brasil. Movimento, Porto Alegre, v. 9, n. 1, p. 145-169, jan./abr. 2003.

NEIRA, Marcos. Alternativas existem! Análise da produção científica em dois periódicos brasileiros sobre a docência na Educação Física. Movimento, Porto Alegre, v. 18, n. 1, p. 241-257, jan./mar. 2012.

PADILHA, Maria; NELSON, Sioban. Networks of Identity: The Potential of Biographical Studies for Teaching Nursing Identity. Nursing History Review, New York, v. 19, p. 183-193, 2011.

REID, Anna et al. Identity and engagement for professional formation. Studies in Higher Education, Local, v. 33, n. 6, p. 729-742, Dec. 2008.

SACHS, Judith. Teacher professional identity: competing discourses, competing outcomes. Journal of Education Policy, London, v. 16, n. 2, p. 148-161, 2001.

SACHS, Judith. The activist teaching profession. Maidenhead: Open University, 2003.

SANCHO, Juana; HERNÁNDEZ, Fernando. La formación del profesorado en tiempos de incertidumbre. Movimento, Porto Alegre, v. 10, n. 1, p. 9-39, jan./abr. 2004.

SANTOS, Núbia; BRACHT, Valter; ALMEIDA, Felipe. Vida de professores de Educação Física: 0 pessoal e o profissional no exercício da docência. Movimento, Porto Alegre, v. 15, n. 2, p. 141-165, abr.jun. 2009.

SAVATER, Fernando. Ética para um jovem. 21. ed. Algragide: Dom Quixote, 2013.

SCHERER, Alexandre; MOLINA NETO, Vicente. O conhecimento pedagógico do professor de Educação Física da escola pública no Rio Grande do Sul - uma etnografia em Porto Alegre.

Movimento, Porto Alegre, v. 7, n. 13, p. 71-80, 2000.

SFARD, Anna; PRUSAK, Anna. Telling identities: In search of an analytic tool for investigating learning as a culturally shaped activity. Educational Researcher, Washington, DC, v. 34, n. 4, p. 14-22, 2005.

SILVA, Rudney; ANDRADE, Alexandro; Zanelli, José. O discurso real e o discurso ideal de professores de Educação Física do ensino superior sobre docência. Movimento, Porto Alegre, v. 16, n. 3, p. 133-154, Jul. /set. 2010. 
STROOT, Sandra; KO, Bomna. Induction of beginning physical educators into the school setting. In: KIRK, David; MACDONALD, Doune; O'SULLIVAN, Mary. The handbook of physical education. London: Sage, 2006. p. 425-448.

TOMLINSON, Peter. Conscious reflection and implicit learning in teacher preparation. part II: implications for. Oxford Review of Education, Oxford, v. 25, n. 4, p. 533, 1999.

WAUGH, Christian; THOMPSON, Renee; GOTLIB, lan. Flexible emotional responsiveness in trait resilience. Emotion, Washington, DC, v. 11, n. 5, p. 1059-1067, 2011.

WENGER, Etienne. Communities of practice: learning, meaning and identity. $17^{\text {th. }}$ New York: Cambridge University, 1998.

WILSON, Suzanne; FLODEN, Robert; FERRINI-MUNDY, Joan. Teacher preparation research: an insider's view from the outside. Journal of Teacher Education, Washington, DC, v. 53, n. 3, p. 190204, May/June 2002.

ZEICHNER, Ken. Novos caminhos para o practicum: uma perspectiva para os anos 90. In: NÓVOA, António. Os professores e a sua formação. Lisboa: Dom Quixote, 1992. p. 115-138

ZEMBYLAS, Michalinos. Emotions and Teacher Identity: a poststructural perspective. Teachers and Teaching, London, v. 9, n. 3, p. 213-238, Aug. 2003. 